\title{
Imagineering: Re-Creating Spaces through Collaborative Art-Making
}

\section{Jo Trowsdale}

University of Warwick, UK

E-mail address: jo.trowdale @ warwick.ac.uk

\section{ARTICLE INFO}

\section{Keywords:}

Creativity

Education

Social interaction

Collaboration

Community arts

Steam education

\section{Article history:}

Received: 15 March 2016

Received in revised form: 27 July 2016

Accepted: 6 September 2016

ISSN: 2354-0036

DOI: $10.1515 /$ ctra-2016-0018

\section{A B S TRACT}

This paper considers the significance of the types of learning relationships developed between children and adults during a creative arts and engineering project: The Imagineerium. It focuses on data collected through observations, 18 interviews conducted during and six weeks after the pupils had been involved in the project, and 25 interviews conducted one year later. This is supported by reference to a wider data set gathered from questionnaires, field notes and journal analysis conducted with 72 pupils. A significant and recurring feature emerging from this data was pupils' perception of the positive relationships they experienced within The Imagineerium project. The article considers the elements of the project that contribute to this relational experience. In particular, it argues the importance of this educational experience being located within a tradition of community arts, within the practice of art-making and involving adult facilitators committed to these practices.

\section{INTRODUCTION}

This article seeks to expound the character and significance of the social interaction and creative processes involved in a particular arts and engineering education project - The Imagineerium. Seventy two pupils, aged 9-10, from three English schools gave a unanimously positive account of their experiences of the project. Drawing on a range of empirical data collected during, and up to a year after their involvement with the project, this paper address two key questions:

- What do the children identify as the most positive aspects of the project?

- What features of the project, and of adults' behaviour within it, appear to correlate with and could be seen to foster these aspects? 
The Imagineerium, is an arts and engineering education project designed on social constructivist principles (Dewey, 1934, 1939, 2011; Vygotsky, 1978) and reflects a view, shared by the author, that we learn by doing, constructing knowledge and meaning from experiences. The practice of doing is thus recognised as a mind-body learning process (Bresler 2004, Claxton, Lucas \& Webster, 2010). Children are received and recognised as imaginative, capable, and as individually and socioculturally motivated. Learning builds upon their dispositions and habits to develop new capabilities, understandings and ways of seeing, such as interaction, creative play and problem-solving.

The article begins by describing and locating the project 'The Imagineerium' and the research methodology adopted. It then focuses on several key aspects, which analysis of the data identifies as significant in explaining pupils' positive responses to the project. These are:

- that the lead practitioners are rooted in community arts practices which are relational and focused on building place, people and community;

- that the project is designed as an imaginative, collaborative and creative endeavour, situated in art-making, in a particular community location and;

- that the resources and 'space' in which the project operates, physical and symbolic, enable the conditions above.

I conclude by considering the implications for education, of socially interactive models of practice, like The Imagineerium, highlighting several points which, whilst recognising the challenges involved, warrant greater attention to develop motivated polymaths, who are interpersonally skilled and fascinated by learning.

\section{INTRODUCING THE IMAGINEERIUM}

The Imagineerium ${ }^{1}$ was launched in 2014 when Imagineer Productions ${ }^{2}$, a cultural events production company, in partnership with engineering companies, piloted a project with three schools. 72 children were presented with a commission as 'young Imagineers' to imagine, design and make three inspirational tricycle powered animated structures to be part of a city cavalcade launching a 'Festival of Imagineers'.

The idea for The Imagineerium grew from a partnership between theatre makers experienced in creating site specific, large scale and community events with a range of engineers with mechanical and technological expertise. It was consolidated through a threeyear project (Godiva Awakes), to imagine, design and construct an appealing, six-metre tall mechanical puppet that could sit, stand and walk, and be transported by a cyclopedia.

\footnotetext{
${ }^{1}$ The Imagineerium refers to the space, physical and symbolic in which people 'imagineer'. The term 'Imagineer', one who imagineers, draws obviously upon the verbs 'imagine' and 'engineer' connoting the hybrid imaginative and inspirational work of artists and engineers working in partnership, and at times interchangeably, to invent.

${ }^{2}$ See http://www.imagineer-productions.co.uk for further information on the company's work and the Imagineerium Initiative
} 
The project theatrically and symbolically 'reawoke' the spirit of Godiva, wife of the Earl of Coventry who demonstrated justice, tolerance and courage when she agreed to ride 'naked' through the city streets to persuade her husband to reduce the taxes on the city's starving poor.

The Imagineerium is very firmly located within the histories, stories and communities of Coventry, a post-industrial city, home of the first safety bicycle, famous for car manufacture and the Godiva legend. When children meet and engage with the mechanised puppet, they are invited to connect with the ideas and values she embodies, as well as the imaginative and skilled design and engineering involved. They have an opportunity to think about who they are and who they might like to be in relation to their city's famous character and the values she represents. This was evident in the concepts children developed for their designs, for example: a golden raining tree, echoing Godiva's generosity; a tree which connects the community and engineers to 'imagineer' ideas, a 22-handed princess, who constructed by hand shapes, physicalises positive human values and behaviours.

Godiva Awakes was an extraordinary project which rallied significant local support and interest ${ }^{3}$ and proposed an inspirational, situated and bespoke model of creative engineering, of 'imagineering' - a trans-disciplinary STEAM model (science, technology, engineering, arts and maths) for education. The Imagineerium emphasised the social significance of the arts in the STEAM agenda - proposing collaborative art-making as its modus operandi and a community, cultural event as the purpose for learning rather than a vehicle for exclusively STEM objectives. In so doing, it advanced the significance of the personal, emotional, relational - collectively, the affective - in creative and learning practice.

\section{THE STUDY}

The study was designed to enable an understanding of the value of The Imagineerium to learners and educators, to understand and begin to evidence its impact on learners. Based on and assuming a widely held understanding that children learn best when engaged and enjoying the experience, the study explored two key research questions:

- What do the children identify as the most positive aspects of the project?

- What features of the project, and of adults' behaviour within it, appear to

correlate with and could be seen to foster these aspects?

The case study design, informed by complexity theory (Byrne 2013; Byrne \& Callaghan 2013), drew upon participatory research methodology (Berghold \& Thomas 2012; Kindon, Pain \& Kesby, 2007) in deploying a range of tools in order to gather multiple perspectives of adults and children involved on a range of aspects of the project. These in-

\footnotetext{
${ }^{3} 17$ engineering companies, 57 businesses, civic partners, 2,500 community participants in live events, 11,000 community participants engaged in formative elements and 540,000 civic and community audience.
} 
cluded semi-structured researcher observations recorded in field notes, structured teacher assistant and pupil observations, questionnaires, project journals, focus groups and individual interviews, and postcard writing. Data were collected about and from 72 children with further, more in-depth, qualitative data drawn from observations, journal analysis or interviews with 18 children. These 18 were selected by teachers to represent children who typically access learning easily $(n=6)$, typically find learning challenging $(n=6)$ and whose experience of learning is varied $(n=6)^{4}$. Interviews were conducted in schoolbased focus groups of 6 at the outset and individually post project. One year after the project, interviews were conducted with 25 children, of whom 16 were in the original sample. These were conducted in groups of 2-5 children, in gender groups, and involved a range of activities: visual, spoken and written in conversational mode. The case study which constitutes the heart of this article specifically draws on data gathered between February 2014 and July 2015.

\section{The significance of community art making}

The artists at the heart of The Imagineerium began work as community artists. Observations of their practice, both within this project - but also over a number of years on other projects reveal that their own identities, practices and interests are rooted in the 'democratic imagination' (Greene, 2000), which characterises both the practice and literature of community arts. These artists often work with the disadvantaged, disenfranchised and isolated in society. They have years of experience in what Meade and Shaw describe as:

entering attentively into the experience of others, excavating and exploring the causes of flaws and wounds in society, thinking critically about structures and relations of power and acting creatively and collectively to transform the world for the better. (Meade \& Shaw, 2007, p. 414)

They share Matarasso's view that community art-making is political and that, as he spells out further, it:

give[s] people access to a means of self-expression, even of self-definition, that no other form of collective action offers ... In a democratic context, cultural expression is a fundamental human right because it allows individuals and groups to define themselves and their beliefs, and not only be defined by others. (Matarasso, 2007, p. 457)

A group of girls reviewing the significance of The Imagineerium pilot project a year on, identified new beliefs and improved self-efficacy as the key value of the project for them. One spoke about a different insight into engineering in society: that 'it's really about using

\footnotetext{
${ }^{4}$ The term 'access learning' here denoted the effective learning behaviours as well as achievement of learners.
} 
your mind' and how it really could appeal to girls. Another spoke of new self-belief: 'Before I'd be "well I won't be able to do that", but Imagineering has opened my eyes and I think "I can do this!" '. A third saw the most important thing as self-discovery: 'finding the parts of you that you've never seen' (Hema, Jasmeen, Maarika \& Earlene, Interview 2015)

A grounding in community arts also explains the lead adult Imagineers' skills in building relationships, evident throughout the project, for example in direct eye contact as they encounter children, using names when talking to each individual, in looking to draw in those on the edges. Imagineers physically entered and stayed in the core social space of the classroom alongside children, rarely taking an obvious position of authority, taking every opportunity to talk and ask questions thereby manifesting a curiosity about and interest in the children. This point was remembered a year on by several children who spoke of the Imagineerium as 'welcoming', about 'feeling a lot more', that Imagineers 'talked to us about stuff', 'were interested in us', 'like you cared' (Almira, Maarika, Madiha \& Louise ${ }^{5}$, Field notes 2014 and Interviews 2015).

The significance of this relational dimension is noted by Matarasso (2012) when considering artists as models for leadership. Here Matarasso draws on the work of Douglas and Fremantle (2007) who suggest artists lead through practice; they are 'inclusive, collaborative, connected.... good negotiator[s]'. He emphasises their relational skills: that they are practiced in 'being with people, working together, responding, interacting' (2012, pp. 6-7). These are the attitudes, the practices and thereby the lived environment children experience in The Imagineerium. Their curiosity is met with interest and enthusiasm; their individual thoughts and opinions are heard and responded to. Children encounter 'the arts' in community contexts as a 'site', in Meade and Shaw's terms, 'where political and pedagogical roles and relations can be renegotiated and re-imagined' (2007, p. 414). This argument has been echoed since, in the work of Thomson et al. (2012) studying the pedagogy of artists working in schools. They suggest that artists construct alternative pedagogic 'platforms' from which different values can be promoted to 'default' pedagogies - a point to which we will return.

That the project was grounded in the 'real world', beyond school and celebrated publicly, as part of a city festival, was significant for the children. Many professed afterwards that they had not quite believed the promise that their ideas would be developed to a full-scale build and made public in their community. One child summarised, to the nodding heads of his peers: 'We got to do some work outside from the school. Like make our ideas.... Make it for real' (Karl, Interview, 2014). This sense reflected a commitment by

\footnotetext{
${ }^{5}$ Names have been changed and are pseudonyms. Sources are all post project interviews, unless otherwise indicated.
} 
the Imagineers to honour the qualities of the children's drawings, using technical expertise to ensure robustness, but not altering the line, shape or spirit of the original. The idea echoes a point increasingly evident across creative city, participatory and other place based art initiatives: that a broad aesthetic, reflective of people and place should characterise our lived environments (Cunningham, 2015).

\section{AN IMAGINATIVE FRAME FOR COLLABORATIVE ART-MAKING}

In the pilot Imagineerium project, the children first encountered the Imagineers when they arrived in their playground one morning cycling a 'travellator' (a platform dressed to suggest a time machine and powered by three tricycles) in search of 'imaginative children' to undertake 'a commission from the city council' 6 . Costumed as early nineteenth Century inventors or aviators, with white collarless shirts, beige trousers, boots, waistcoat, neckscarf, long brown coats, flying helmets and goggles, the Imagineers looked unusual. They invited their way in, carrying leather suitcases and chests which revealed clues to be explored through drama and group based activities. Imagined and real, past and future collided as the task was revealed: a real task, presented by extraordinary people, related to the history and myths of the children's city, and an invitation to be part of the future.

Interviews with Imagineers' revealed their intentions to create an 'irresistible imaginative' frame to 'hook children's interest' (Pre project Imagineer interviews, 2014); this introduction formed an 'imaginative invitation' which, as Cunningham suggests, like ‘[t]he best of socially engaged practice takes into account the motivating factors that tempt people to take part in something' (2015, p. 22). Children's reflections on the experience in journals and interviews reflect a shared sense of curiosity and excitement.

"When you drove the travellator round and I found out that it was for our class ... that [was] really exciting - Something was going to happen!" (Abaar, Interview, 2014)

"I was walking to school when we saw the travellator coming along and [the Imagineers] started asking me questions ... and then it came into our playground!" (Kiran, Interview, 2014)

"The Imagineers ... were dressed in ... (falters) ... Englishmen's clothes. They ... they had a treasure chest and I was thinking what was inside and that made you really excited." (Madiha, Interview, 2014)

The challenge, its scale and source, generated excitement and some anxiety simultaneously. But the overriding response was that this fantastical group of people offered an

\footnotetext{
${ }^{6}$ The terms 'travellator', imaginative children' and 'commission from the city council' were terms used repeatedly by the Imagineers in the first sessions in schools. Some also appeared in the written commission they were presented with to launch the project.
} 
adventure which looked like it would be 'fun'. Certainly the two words 'fun' and 'excited' were the most frequently written and spoken in reflecting on the experience.

In the opening sessions, children sat in a circle and, using a drama 'Whoosh', performed a short story of the hummingbird - the animal who, in the face of bigger more capable animals taking no action to allay a fire which has broken out in the jungle, persists in repeatedly taking a drop of water in his beak to 'do what he can' to quench the flames. Children immediately understood the significance of the narrative to their own task and it became a reference point for collaboration as well as persistence. They were given hummingbird badges as a reminder of this behaviour and in interviews often referred back to their work ethic to 'never give up' and 'do the best I can' inspired by this idea.

The experience of the 'whoosh' also emphasises every child in the circle as part of an ensemble: children are quickly and minimally signalled to enter the space to physicalise objects and people together through still image and actions, to leave and a moment later to re-enter in a different role. The storyteller signals action through narration, so children must attend to the signals to keep the story going for the group. The story is focal and cooperation essential. Combined with the 'quintessentially collaborative' - ensemble - (Boyd, 2004) nature of this applied theatre form, the hummingbird story signified not just 'inspiration' to persist in the face of challenges, but also provocation to collaborate - a point evident in journals, within project discussions and post project interviews.

\section{COLLABORATIVE ART-MAKING}

The professional practices of the Imagineers characterises the work and work ethic into which children are inducted - a point expanded on below. Physical performance-based practices are used dually in the project design: to enable children to experience their bodies as exquisite pieces of engineering, capable of aesthetically pleasing effects and as means of enjoying learning. Through a series of contact improvisation based activities, interwoven with questions drawing attention to the physical sciences (the concept of forces and the mechanical advantage of mechanisms) children learnt about push and pull, counterbalance and counterweighting, centre of gravity, bracing, levers, cams and pulleys. Questionnaire results suggested that using physical theatre and working manually with materials were, for over $80 \%$ of children considered highly effective in helping them to understand physical science concepts and, for some, the process of translation from 'being felt within the body' to 'being felt in the hands' was significant in stimulated thinking. Activities involved demonstrations and testing by the children: of the use of push and pull to speed up, slow down, change shape and change direction; of finding counterbalance through bracing in pairs, with toes touching each other, holding wrists, stretching out arms and leaning back; of groups testing stability of different braced structures, such as 
pairs finding the pivot point for balance of one person stretched out on another. Often Imagineers would use aesthetically pleasing and impressive skilled movements and shapes to show how the same principles were at play in movement based theatre. They tested ideas to explore what needs to be altered to improve a hard activity (such as a bent arm as short lever) into an easier one (an extended arm as a longer lever). Activities in which children were experiencing their arms acting as braces or testing in pairs to find the effort each needed to exert to find the counterbalance for secure stillness proved to be a great reference point for knowing how to build effective structures with sticks and potatoes as prototypes for their designs.

But beyond the 'fun', 'entertainment' and scientific understanding that children noted in questionnaires and interviews, the use of physical theatre as a learning medium was also significant in advancing other aspects. Whilst counterbalancing, children were making eye contact; whilst working physically, they were touching and attending to each other more carefully - all of which appeared significant in building the trusting foundations for collaborative work. The affective dimension that such contact and the physical medium can generate is also significant. This is an aspect we have attended to further in subsequent and current projects. In a recent project, a group of girls working to develop a robust, three-dimensional group structure identified a triple wrist hold centrally and then tested the arrangement of feet to create a triangular shape. In the process some wobbled and instinctively moved their bodies, looking nervous or apologising. Through talking about how this made them feel emotionally, they were able to trust their physical instincts to move their feet, to talk openly about using elbows or feet in order to add additional bracing. The notion that the emotions are to be trusted as ways of knowing and can be spoken of and shared, whilst uncommon, is gaining ground (Clough, 2007).

Children were facilitated to imagine and sketch ideas in a range of ways, to a given stimulus, to develop new ideas in pairs from existing individual ones, to combine ideas in groups. The experience of collaboration, both here in idea generation, in physical tasks and, later, when children were allocated specific additional roles in their group, was recognised by children as positive and important in developing the quality of their ideas and thinking. Children across the ability range and with varying interests and learning preferences spoke of positive effects of group interaction - this was evident in questionnaires, through observed conversations and interviews. Some children attributed their achievements in the project to collaborative practice. A year on, most of the children interviewed spoke of the project being about 'teamwork' and what they had learnt from this emphasis. Almost all children interviewed thought they worked better and learnt more with others than alone and comments such as these were typical: 
"I get inspired by other people in my group" (Haroon, Interview, 2014).

"I like learning from other people" (Adrian, Interview, 2014).

"I find everyone's ideas helpful because .... everyone thinks different - no one thinks the same as anyone else so you can learn from other people as well (Kiran, Interview, 2014).

It helped me to work with new partners - people I don't generally work with" (Madiha, Interview, 2014).

Their comments reflect Vygotsky's (1978) famous theory of the zone of proximal development, that through working (or experimenting) with more (or differently) experienced others, a child may develop further than if he/she approached the same challenges alone. Whilst for Vygotsky the 'more experienced' might be older experts, here a mix of 'expert' adult Imagineers operate alongside the more horizontal relationship with peers which recognises expertise in different aspects of the work. This generates a positive and broader conception of what expertise might look like. Learning from peers was mentioned frequently in the data, as was the positive experience of contributing one's expertise to the group. This was reported as being affirming for the children involved. At times, adult Imagineers were significant in developing children's understanding and practice and worked for extended periods with individuals. But often learning would be worked out between children following observed or momentary suggestions from an adult. Children saw the character of group work, as they experienced it the Imagineerium, as different from 'usual'. The words 'with', 'from' and 'by' in the children's voices above perhaps suggest a more engaged and attentive interaction with each other, to the 'alongside' sense of being placed in a group - for these children at least.

At times, Imagineers facilitated or scaffolded some group interaction. They modelled listening and responding; helped children to identify possible connections and aided negotiation of emergent new ideas. Children recognised that this was helpful because 'we had ... different ideas and we all wanted our ideas to be put in and sometimes we couldn't develop them because we didn't know how to put them together' (Adila, Interview, 2014). Indeed, as identified here, the process of negotiating a collective rather than individual way forward, of developing an idea collaboratively can be a source of conflict. Perhaps it also reflects inexperience or lack of confidence with the creative process of making whereby 'a vision emerges through the creative process rather than being established beforehand and worked towards' (Matarasso, 2012, p. 7). Certainly some children suggested that at school 'we don't usually get to be that creative and think of ideas like that' (Adila, Interview 2014) or 'normally we don't get to get our creative sides out' (Adrian, Interview, 2014). An interesting and haunting comment was made by one 
who reflected that working with Imagineers and peers had generated new thinking for him because 'at school we don't get to think a lot' (Abaar, Interview, 2014). Teachers affirmed that monitoring of assessment, school inspection and curriculum requirements constrained the time they would like to give to developing children differently and to more collaborative ways of learning.

The social desire to 'help my team mates' (Issac, Interview, 2014) and 'cooperate with my team' (Abaar, Interview, 2014), was a common theme of interviews. The practice of group work led children to negotiate better where they experienced challenge so that they 'started combining all of our ideas' (Dakota, Interview, 2014). This behaviour is evident in children from the early years who invent a story together through, not before, playing a role, negotiating and adapting the rules they had established a moment earlier in order to develop the story. This same habit, noted by Sawyer (2007, pp. 21-22) as an improvisatory and creative habit was evident in The Imagineerium with children collaboratively changing previously agreed ideas as new ones emerge and are deemed better. Sawyer, who argues that creativity is an interactive, group process, notes that Csikszentmihalyi's (1990) research into 'flow' (the state of immersion, optimum focus and learning) 'found that the most common place people experienced flow was in conversation with others' (1990, p. 22). Indeed, he suggests that even 'the insights that emerge when you are completely alone can be traced back to group collaboration' and 'a string of successive ideas each spark lighting the next' (1990, p. 4). One of the girls explained how her idea grew through group talk: 'I felt they were improving my idea' noting that one key visual aspect 'never really had a meaning until the group started talking about it' (Earlene, Interview, 2014).

Although the character of collaboration and the efficacy of group practice fluctuated from group to group, within and between sessions, children's awareness of their and peers' strengths typically developed. Involving children as occasional coresearchers (noting observations and comments within their team with regard to particular creative learning behaviours, including collaboration), may have fed such awareness. A year on, one of the girls interviewed talked about learning to think together' (Jasmeen, Interview, 2015) through the experience of the project. Her comment was part of a wider discussion (detailed above) characterised by peers' noting improved self-efficacy. Her particular comment echoed Matarasso's argument that 'the arts have the potential to define and symbolize alternative realities and that, 'working through them can build people's capacity for, and interest in, shared enterprise. They can form a nucleus of self-determination' (2007, p. 457). These four girls appeared to represent a new found self-determination as they spoke of the new habits of making, researching, journaling and self-belief they had developed. 


\section{A SENSE OF PLACE; A KIND OF SPACE}

The physical Imagineerium space is an industrial warehouse - the former powerhouse of the Daimler car industry, a heritage site, located centrally in the city, near the canal basin. This location is significant as a potential 'creation centre' which young people, the community, as well as professionals, can access easily to collaborate. It has elegant arched windows within a brick skeleton and concrete floor. Two thirds of the space is on two levels. One industrial air heater can blast warmth in the downstairs workshop. Some heat filters upstairs to the rehearsal studio, but it is a cold space. Costumes from carnivals and events line the rehearsal studio; materials, recycled and found 'stuff' and old models and work in progress surround the tables in the main workshop. The remaining third of the building, which can just house a standing 6 metre tall Godiva, goes to the ceiling where the heavy metal work which once formed the structure for the loading bay on to the canal now provides a rig for rehearsing aerial performance.

Girls spoke of the daunting sense the 'hard grey metal' suggested from outside which contrasted with the amazement of Godiva and the products of imagineering, the delight of 'the colours and exciting materials' inside (Field notes, 2014). Indeed, one of the delights of the Imagineers is to greet children outside and see their faces change as they step through the door to be greeted by Godiva - typically animated and accompanied by her slightly ethereal music.

Children are reminded ${ }^{7}$ that this is a professional, albeit a 'messy' working space and that some tools are out of bounds for their safety, but they have access to all spaces and over their time at The Imagineerium, get to work in all: the workshop, around Godiva, in the studio and outside. Within the workshop, each group has a work station but all are given permission to move around, use the floor, find a different space as the task they are engaged in dictates. They are given freedom to use most materials and Imagineers work with them.

Questionnaire analysis revealed that all children felt inspired by experiencing The Imagineerium space. For many, seeing Godiva mechanically animated at The Imagineerium was the highlight. $94 \%$ of children rated highly 'seeing creatively engineered products like Godiva and the Hummingbird' (Godiva's electronic flying bird). They relished the creative character of The Imagineerium as a physical space which had significance for them as the place 'where Godiva and the Hummingbird was made' (Abaar, 2014) and as a resource-ful space where they 'felt creative'. The challenge in learning contexts of the 'messy' (Gryskiewicz, 2009, p.100) and 'unpredictable' (Runco, 2007, p. 178) na-

\footnotetext{
7 The decision to use the present tense here is a deliberate decision, reflecting anthropological practice, to generate a sense of 'being there' (Geertz 1988) and seeking to convey a feeling of the immediacy of the experience. It also emphasises The Imagineerium as a live project - with continuity; not something which belongs in the past.
} 
ture of creativity felt more possible, and full of possibilities here. Children enjoyed being able to 'move about a bit' (Azaad, 2014), 'to use different spaces' (Field notes, 2014), 'special places .... and so many different things that you could use' (Malwina, Interview, 2015) and the freedom and control to choose and decide certain elements:

"We were allowed to use whatever we wanted ... sometimes we get to do art at school but we're not allowed to choose what we want to do - [in The Imagineerium] we were allowed to use different materials and not just drawing" (Adila, Interview, 2014).

The allocation of roles which gave children a particular responsibility added motivation to their engagement with the project and the spaces used.

"We - only us, me and one other person, we only get to choose the colour and design ... we were choosing them" (Zabia, Interview, 2014)

Reflecting back on the project, children said that they 'felt trusted' to attempt challenging tasks, which in turn made them feel capable and positively shaped their self belief. The mix of activity and expertise fostered a range of approaches and problem solving. Children roamed and observed, focused and tested, talked and sought advice in fluid and responsive ways. Often suggestions would come from an Imagineer seeing a possible connection and proposing a reference or collaboration, but these also occurred organically. Glaveanu's attention to the increasingly popular 'we-paradigm' in the creativity literature as 'distributed creativity' is especially useful here, emphasising the dynamic and live nature of creativity which is generated between 'people, objects and places' $(2014$, p. 8)

In their analysis of artists working in schools, Thomson et al. (2012) talk about the 'third spaces', the 'non-spaces' that artists generate, of the 'sociality' of such 'meeting spaces' and of the 'mobility' that characterise them (p. 18). As discussed above, the Imagineers use of space and climate they generate both in school spaces and The Imagineerium echo this sense of sociality, of meeting, where the human relationship is recognised as a primary motivating factor in engagement. This was evident in the heightened interest children demonstrated the moment an Imagineer was in sight - in anticipation of the forthcoming activity. Increasingly, children would congregate at any possible opportunity to talk to an Imagineer who would typically be responsive to the children's interests and forthcoming about themselves and their work.

\section{THE PRACTICE OF IMAGINEERING}

Imagineers, like the artists in schools Thomson et al. studied, introduce 'the absurd or carnivalesque' (2012, p. 17). They enter the 'school space dressed and behaving differently', are 'larger than life' and introduce 'a light-hearted disruption' to school. They welcome and promote playful behaviour. Such behaviour constitutes an invited disturb- 
ance' (Trowsdale, 2005, p. 36) to typical school routines, but, as the term suggests, is an intentional and conscious invitation by schools, who invite Imagineers in, as disruption of more regular schooling, a reframing and thereby a means of expanding how children learn. Dewey draws our attention to the significance of the aesthetic in art-making: to the sensitising, attunement and thereby more expansive learning that experiencing art generates. In comparing the aesthetic with the 'anaesthetic' he emphasises the significance of the arts to 'break through the crust of conventionality ... reject the static, the automatic, the merely habitual' (Dewey, 1934, p. 48). Albeit playful in appearance, schools and Imagineers are partners in such a process.

Tinkering, experimenting, generating and trying out ideas with humour, disruptive intent, questioning and gentle mocking can accompany learning every bit as meaningful as that acquired through quiet contemplation (Thomson et al., 2012, p. 17).

The teacher interviews revealed the delight they had in children trying out practical and interactive learning which was more 'open-ended' and encouraged 'possibility-thinking' (Craft 2000). Many enjoyed the Imagineer personalities and noted that it gave them permission to move within such behaviours themselves at times. Having to deal with the unknown, unclear or with 'failure and disagreement' were recognised as valuable by them too.

Earlier we noted children's response to the arrival of the Imagineers and the social and relational behaviour of Imagineers in the school space - two specific examples of 'disruption' of the norm. Their practice forms another. Children were very aware of the common and specialist skills of each Imagineer. Their comments reveal that, overall, they saw them as very 'skilled', 'quick', 'straight on it', 'doing it', 'helping', 'full of ideas' and 'inspirational' (varied interviews). They were aware that Imagineers would try out, experiment and test ideas, materials and processes and that they had permission and encouragement to do the same. This modelling, which very deliberately demonstrated both the 'know-how' of the practice and its interactive character often generated talk about the practice of Imagineers, but also validated the creative, making process as a 'going through' (Ingold, 2014), the 'experience' of art-making as 'learning' (Dewey, 1934). In a different Imagineerium project, we have articulated in written form, as part of the engagement of children, how Imagineers behave such as 'having fun at every opportunity ... dreaming ... being resourceful, ... taking responsibility for a role ... seeing the good things about "failing"' as well as 'staying true to the project brief' (Project materials, Imagineerium Project, 2016). But in the pilot project discussed here, these understandings were part of the lived experience children gained of Imagineering and their post project 
reflections reflect these same ideas. Evident from observations, but also acknowledged by teacher interviews, children thought they were 'just more confident in everything' (Maarika, Interview, 2015), more 'ready to have a go' (Jasmene, Interview, 2015).

"I decided I was going to do more art ... and I have ... I make things" (Louise, Interview, 2015).

"I'm not a fan of art, but Imagineering ... taught me that you don't need to always draw everything, you can write your ideas down using your brain ... create from .... your thoughts" (Hema 2015).

The daily practice and know-how of the Imagineers constituted a significant motivating factor to the children, $80 \%$ of whom, after the project, considered Imagineers had helped them learn or engage with learning and who almost exclusively (97\%) had valued the experience of 'model making in The Imagineerium with skilled artists, designers and engineers'. A year on, conversations with the 25 children interviewed echoed the importance of this aspect of the experience.

Following Lave and Wenger (1991), the project, designed around a commission for a piece of work to be built for an event, 'takes as its focus the relationship between learning and the social situation in which it occurs' (p. 14) with an added awareness that only one design from a class could be built to full scale, so groups were competing to create imaginative, persuasive and high quality models - learning together both collaboratively and competitively. Children were intrinsically interested - $90 \%$ of children reported highly valuing working 'as if in a professional design team' on a real commission.

Some children gravitated towards particular Imagineers due to interest in their apparent specialism - for example in design ideas, in structural skill as an engineer, or in overall concept as a performance director. Gender differences were noticeable with some children, typically boys, fascinated by the engineers,

"I liked learning the technical stuff about building - Phil and Roger taught me a lot" (Adrian, Interview, 2014).

and some girls seeking advice and support from the designer makers,

"I learnt lots of things from Kathi she taught me to gluegun padding to shape a belly" (Maarika, Interview, 2014).

Imagineers showed children their own work journals - some more visual, some more wordy - as examples of how they gathered ideas they had researched or been inspired by, sketched or wrote things they wanted to remember from work sessions, or thoughts about ideas they were developing and also reflected on how their experiments had gone. Children were given blank paged journals to do the same as 'young Imagineers'. At times, they were asked to note thoughts, sketch or annotate a sketch with ideas. Typi- 
cally they sketched more than they wrote. Journals were used sometimes intensively but more 'as and when'. They were not necessarily directed to be reflective in character, but captured moments in time. Seventeen of the eighteen children interviewed after the project felt that the journals were important to them, signifying the voice they had been given in the project - to articulate their own ideas, and as a way to share their ideas with others in a way that would not be judged. They saw the journal as a place where 'it doesn't matter if you get a mistake' (Zabia, Interview, 2014), where 'we can sketch our own stuff' (Adila, Interview, 2014) or 'put down what was on our mind' (Adrian, Interview, 2014), that 'it's yours' (Malwina, Interview 2014) and 'you don't have to show anybody' (Earlene, Interview, 2014).

\section{CONCLUSION}

Children reported that learning through the Imagineerium project was a positive experience, with some clear differences from the way they typically experienced learning. The research into this project has highlighted a number of significant factors, which are important in understanding learners' attitudes and which are informing how we develop future iterations of The Imagineerium. This also has potential wider resonance for others in shaping and developing educational projects. The social relations between young people and adults are strikingly central in developing positive accounts of learning from the children and appear to underpin and relate closely to other aspects, illuminating the fact that / or the notion that/ idea/ that educationalists might attend further to fostering the collaborative and relational aspects in learning. Here I conclude with three related aspects that such a shift demands.

Firstly, the dramatic, imaginative frame emphasises the significance of an ensemble -based and possibility-thinking mindset; it underpins first encounters with the Imagineers, the commission and then the physical Imagineerium. Although the commission in 2016 is a different one from the one reported here and the first encounters have been realised differently, the social interaction of the costumed Imagineers and their enticing commission have still drawn in teachers and children irresistibly 'because it's so exciting', 'so imaginative' and '[you] want to do it - be part of it' (Field notes 2016). (It should perhaps be noted here that by recognising evidence of how a dramatic and imaginative frame draws children in and together, I am not discounting the on-going challenge of the collaborative process. Ensemble and team-work requires ongoing practice in the complex, negotiated dance through individual and collective motivations).

A second factor we are attending to and developing is the intensely embodied and practice-based dialogic processes, focused on a shared task, which characterise school and Imagineerium based sessions. These foster the recognition of diverse ways of know- 
ing, individual ideas, feelings and strengths within a collective, generating possibility thinking (Craft, 2000) and expansive conversation. The Imagineerium becomes a physical and metaphoric space for playful work in which the relational is central in a shared enterprise to produce inspirational work for performance events - events which will have resonance locally and beyond.

A third factor relates to the Imagineers themselves. Imagineers are not yet a multitude. They are self selected partners, whose interest in inventing fantastical performance events and belief in young people as full of creative potential bring them together in this enterprise. They are attuned to young people, with developed relational skills for collaboration. They recognise they are role models for openness, curiosity, for experimenting, failing and learning, for imagining, and respecting each other's views, learning from difference and helping each other. As we expand the project this year, and the range and number of partners involved, we are mindful of lessons from the pilot project: That it is not sufficient to assemble people with special expertise from different disciplines to 'imagineer'. Values and ways of being need to be aligned - the histories and contexts of practice need considering in the initiation of new Imagineers. There is a careful observation, absorption and development of shared values to be enabled. As we attend to the attunement required, we are conscious of the particular lead that arts based Imagineers take in developing the behaviours and ethos of The Imagineerium. Developing this attunement and aligning values remains a challenge for us and for others engaged in similar enterprises.

This is unashamedly a descriptive case study, seeking to illustrate empirically how we might think of learning differently. It is a story of how children can re-imagine their futures, from their local and personal pasts and presents: how they can live in a dynamic of becoming and how important others are in that process.

\section{REFERENCES}

Berghold, J. \& Thomas, S. (2012). Participatory Research Methods: A Methodological Approach, Motion, Forum: Qualitative Social Research 13(1).

Boyd, M. (2004). Ensemble Theatre Conference Transcript. The Barbican, London $23^{\text {rd }}$ November. Retrieved from http://www.dggb.org/files/EnsembleTheatreConf.pdf Bresler, L. (Ed.) (2004). Knowing Bodies, Moving Minds: Towards embodied teaching and learning, Dordrecht, Netherlands: Kluwer Academic Publishers .

Byrne, D. (2013). Evaluating Complex Interventions in a Complex world. Evaluation 19(3), 217-228.

Byrne, D. S. \& Callaghan, G. (2013). Complexity theory and the social sciences: The state of the art. London: Routledge. 
Claxton, G., Lucas, B. \& Webster, R. (2010). Bodies of Knowledge. London: The Edge Foundation.

Craft, A. (2000). Creativity Across the Primary Curriculum. London: Routledge.

Cunningham, J. (2015). Knitting Together Arts and Social Change. London: RSA.

Clough, P. (2007). The Affective Turn - Theorising the social. Durham: Duke University Press.

Csikszentmihalyi , M. (1990). Flow: the psychology of optimal experience (1st ed.). New York: Harper \& Row.

Dewey, J. (1934). Art as Experience. New York: Perigee.

Dewey, J. (1939). Creative Democracy: The Task Before Us. Progressive Education Booklet No. 14. Columbus, Ohio: American Education Press. Retrieved from http://www.beloit.edu/ pbk/dewey.html

Dewey, J. (2011). Democracy and Education: An Introduction to the Philosophy of Education. Simon and Brown.

Douglas, A. and Freemantle, C. (Eds.) (2007). Leading Through Practice. Newcastle: a-n The Artists Information Company. Retrieved from https://www.academia .edu/4489290/ Leading_through_Practice.

Geertz, C. (1988). Works and Lives - The Anthropologist as Author. Stanford: Stanford University Press.

Glaveanu, V.P. (2014). Distributed Creativity. London: Springer.

Greene, M. (2000). Releasing the Imagination, San Francisco: Jossey-Bass.

Gryskiewicz, S. (2009). In Rickards, T., Runco, M. and Moger, S. (Eds.), The Routledge Companion to Creativity. London: Routledge.

Ingold, T., (2014). The creativity of undergoing. Pragmatics \& Cognition. 22(1), 124-139.

Kindon, S., Pain, R. \& Kesby, M. (2007). Participatory Action Research Approaches and Methods: Connecting People, Participation and Place. London: Routledge.

Lave and Wenger (1991). Situated Learning: Legitimate peripheral participation. Cambridge: Cambridge University Press.

Matarasso, F. (2007). Common ground: cultural action as a route to community development. Special Issue: Community Development and the Arts: Reviving the Democratic Imagination. Community Development Journal, 42(4) 449-458. doi: 10.1093/cdj/ bsm046

Matarasso, F. (2012). The Art of Uncertainty, Version 4.2. Retrieved from https://www. academia.edu/1217817/The_Art_of_Uncertainty_2012Art_practice_and_leadership_ at_a_time_of_crisis 
Meade, R. \& Shaw, M. (2007). Community development and the arts: reviving the democratic imagination. Community Development Journal. 42(4), 413-421. doi:10.1093/cdj/ bsm032

Runco, M. (2007). Creativity: Theories and Themes: Research Development and Practice. Amsterdam: Elsevier Press.

Sawyer, K. (2007). Group Genius: The Creative Power of Collaboration. New York: Basic Books.

Thomson, P., Hall, C., Jones, K., Sefton-Green, J. (2012). The Signature Pedagogies Project: Final Report. London: Culture, Creativity and Education.

Trowsdale, J. (2005). Cultivating Creativity - Report. University of Warwick. Retrieved from https://www2.warwick.ac.uk/fac/soc/cedar/projects/completed06/teachcreat/ teachcreative06.pdf

Vygotsky, L. (1978). (Ed Cole et al.). Mind in Society. Cambridge: Harvard University Press.

Corresponding author at: Jo Trowsdale, University of Warwick, Coventry CV4 7AL, UK E-mail: jo.trowdale@warwick.ac.uk 